Article

\title{
Cerium (IV) sulfate: A highly efficient reusable heterogeneous catalyst for the one-pot synthesis of 2,3-dihydroquinazolin-4(1H)-ones under solvent-free conditions
}

\author{
Abolghasem Davoodnia*, Maryam Khashi, Niloofar Tavakoli-Hoseini \\ Department of Chemistry, Mashhad Branch, Islamic Azad University, Mashhad, Iran
}

A R T I C L E I N F O

Article history:

Received 27 December 2013

Accepted 20 January 2014

Published 20 July 2014

\section{Keywords:}

Cerium (IV) sulfate

2,3-Dihydroquinazolin-4(1H)-ones

Heterogeneous catalysis

Solvent-free conditions

\begin{abstract}
A B S T R A C T
Cerium (IV) sulfate tetrahydrate, $\mathrm{Ce}\left(\mathrm{SO}_{4}\right)_{2} \cdot 4 \mathrm{H}_{2} \mathrm{O}$, is a novel inorganic solid acidic catalyst that efficiently catalyzes the synthesis of 2,3-dihydroquinazolin-4(1H)-ones via the one-pot three-component reaction of isatoic anhydride, aromatic aldehydes, and a nitrogen source (ammonium acetate, ammonium carbonate, ammonium chloride, or methylamine) under solvent-free conditions. The desired products are obtained in short reaction time with high yields. The catalyst is inexpensive and readily available and can be recovered conveniently and reused such that considerable catalytic activity can still be achieved after the fifth run. Easy work-up and avoiding the use of harmful organic solvents are other advantages of this simple procedure.
\end{abstract}

(C) 2014, Dalian Institute of Chemical Physics, Chinese Academy of Sciences. Published by Elsevier B.V. All rights reserved.

\section{Introduction}

Multi-component reactions (MCRs) are a promising and important field of chemistry because the synthesis of complex molecules can be achieved in a fast, efficient, and time-saving manner without the isolation of any intermediates. Organic chemists have therefore become interested in developing novel MCRs or improving known MCRs [1-3]. One such reaction is the synthesis of 2,3-dihydroquinazolin-4(1H)-ones.

2,3-Dihydroquinazolin-4(1H)-ones are an important class of fused heterocycles with a wide range of pharmacological and biological activities, which include antifertility, antibacterial, antitumor, and antifungal applications [4,5]. Therefore, considerable efforts have been made to explore new simple and direct approaches towards the construction of 2,3-dihydroquinazolin$4(1 H)$-one skeletons. Several methods for the synthesis of these compounds have been reported in the literature. One method involves the condensation of aldehydes with anthranilamide using various promoting agents [6-9], but this is only suitable for the synthesis of 2-substituted-2,3-dihydroquinazolin$4(1 H)$-ones. Other methods include reduction of quinazolin$4(3 \mathrm{H})$-ones using sodium borohydride or sodium cyanoborohydride in acetic acid [10], condensation of anthranilamide with benzyl followed by base-catalyzed hydrolysis [11], and a two-step synthesis starting from the reaction of isatoic anhydride and amines, then ring-closing with ketones [12]. The most straightforward procedure for the preparation of 2-substituted- and 2,3-disubstituted-2,3-dihydroquinazolin$4(1 H)$-ones involves the one-pot three-component reaction of isatoic anhydride, aromatic aldehydes, and a nitrogen source such as ammonium acetate or primary amines in the presence of various catalysts. These catalysts include [bmim] $\mathrm{HSO}_{4}$ [13], silica sulfuric acid [14], p-toluenesulfonic acid-paraformaldehyde copolymer (copolymer-PTSA) [15], trifluoroethanol [16], thiamine hydrochloride [17], Cu-CNTs nanocomposite under microwave irradiation [18], aluminum methanesulfonate [19],

\footnotetext{
*Corresponding author. Tel: +98-511-8435000; Fax:+98-511-8424020; E-mail: adavoodnia@mshdiau.ac.ir, adavoodnia@yahoo.com This work was supported by Islamic Azad University, Mashhad Branch as research project (92429/302/64). 
montmorillonite K-10 [20], silica-bonded $S$-sulfonic acid [21], acetic acid [22], $\mathrm{KAl}\left(\mathrm{SO}_{4}\right)_{2} \cdot 12 \mathrm{H}_{2} \mathrm{O}$ [23], silica-bonded $\mathrm{N}$ propylsulfamic acid [24], and magnetic $\mathrm{Fe}_{3} \mathrm{O}_{4}$ nanoparticles [25]. However, some of these methods have disadvantages such as long reaction time, expensive catalysts, and using microwave irradiation for accelerated synthesis. Therefore, the discovery of a new and efficient catalyst with high activity, short reaction time, and simple work-up for the synthesis of 2,3-dihydroquinazolin-4 $(1 H)$-ones is of prime interest.

Recently cerium (IV) salts have been used for many organic transformations such as the synthesis of carboxylic esters from alkenes [26], synthesis of acetamido phenols [27], conversion of oximes into aldehydes and ketones [28], and one-pot synthesis of 3-acylisoxazoles or polyhydroquinolines [29,30]. The cerium (IV) salts act as Lewis acids in all of these reactions. To the best of our knowledge there are no examples of the use of $\mathrm{Ce}\left(\mathrm{SO}_{4}\right)_{2} \cdot 4 \mathrm{H}_{2} \mathrm{O}$ as catalyst for the synthesis of 2,3-dihydroquinazolin-4(1H)-ones.

As part of our research program directed towards the development of expedient methods using reusable catalysts for the synthesis of organic compounds [31-38], we have recently successfully applied $\mathrm{Ce}\left(\mathrm{SO}_{4}\right)_{2} \cdot 4 \mathrm{H}_{2} \mathrm{O}$ to the synthesis of tetrahydrobenzo[a]xanthene-11-ones [39] and in the protection of aldehydes as 1,1-diacetates [40] under solvent-free conditions. This reusable heterogeneous solid acidic catalyst performs well and shows high catalytic activity. These results encouraged us to investigate the use of $\mathrm{Ce}\left(\mathrm{SO}_{4}\right)_{2} \cdot 4 \mathrm{H}_{2} \mathrm{O}$ in the synthesis of $2,3-$ dihydroquinazolin-4(1H)-ones in a one-pot three-component reaction of isatoic anhydride $\mathbf{1}$, aromatic aldehydes 2 , and a nitrogen source $\mathbf{3}$ (ammonium acetate, ammonium carbonate, ammonium chloride, or methylamine) under solvent-free conditions.

\section{Experimental}

A general procedure for the synthesis of 2,3-dihydroquinazolin-4(1H)-ones $\mathbf{4 a - 4 k}$ is as follows. A mixture of isatoic anhydride 1 ( $1 \mathrm{mmol}$ ), an aromatic aldehyde 2 (1 mmol), a nitrogen source (ammonium acetate $1.2 \mathrm{mmol}$, ammonium carbonate $0.6 \mathrm{mmol}$, ammonium chloride $1.2 \mathrm{mmol}$, or methylamine $1.2 \mathrm{mmol})$, and $\mathrm{Ce}\left(\mathrm{SO}_{4}\right)_{2} \cdot 4 \mathrm{H}_{2} \mathrm{O}(0.03 \mathrm{mmol}, 3 \mathrm{~mol} \%$ based on isatoic anhydride) was heated in an oil bath at $120^{\circ} \mathrm{C}$ for 30-50 min and monitored by TLC. Upon completion of the transformation, the reaction mixture was cooled to room temperature, and hot ethanol was added. The precipitated catalyst was collected by filtration, and the filtrate was cooled to room temperature. The crude product was collected and recrystallized from ethanol to give compounds $\mathbf{4 a - 4 k}$ (Scheme 1).

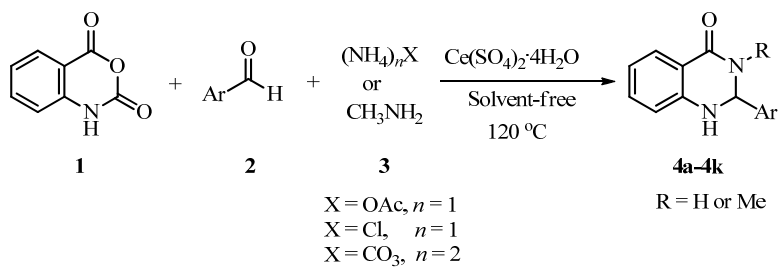

Scheme 1. $\mathrm{Ce}\left(\mathrm{SO}_{4}\right)_{2} \cdot 4 \mathrm{H}_{2} \mathrm{O}$ catalyzed synthesis of 2,3-dihydroquinazolin$4(1 H)$-ones.
The melting points were recorded using a Stuart SMP3 melting point apparatus. The IR spectra of the products were obtained with $\mathrm{KBr}$ disks using a Tensor 27 Bruker spectrophotometer. The ${ }^{1} \mathrm{H}$ NMR spectra were recorded using Bruker 400 $\mathrm{MHz}$ and $500 \mathrm{MHz}$ spectrometers.

\section{Results and discussion}

We first examined the reaction by using isatoic anhydride (1 mmol), benzaldehyde ( $1 \mathrm{mmol})$, and ammonium acetate (1.2 mmol) as model substrates for the synthesis of compound $\mathbf{4 a}$. We decided to investigate the efficiency of $\mathrm{Ce}\left(\mathrm{SO}_{4}\right)_{2} \cdot 4 \mathrm{H}_{2} \mathrm{O}$ in the synthesis of 2,3-dihydroquinazolin-4(1H)-ones under solventfree conditions, which offers several advantages such as being environmentally friendly, simpler work-ups, cleaner products, enhanced selectivity, reduction of by-products, and faster reactions. To find the optimum reaction conditions, different parameters were studied for the formation of compound $\mathbf{4 a}$. The results are summarized in Table 1. First, the model reaction was carried out without any catalyst at high temperature under solvent-free conditions. No product was observed even after prolonged reaction time (entry 1 ). Varying the percentage of the catalyst showed that $3 \mathrm{~mol} \%$ of $\mathrm{Ce}\left(\mathrm{SO}_{4}\right)_{2} \cdot 4 \mathrm{H}_{2} \mathrm{O}$ is sufficient to push the reaction to completion within 45 min (entry 7). The effect of reaction temperature on the output was also investigated, and the optimum temperature was found to be $120{ }^{\circ} \mathrm{C}$ (entry 7). Next, the reaction was performed in the presence of 3 mol\% of $\mathrm{Ce}\left(\mathrm{SO}_{4}\right)_{2} \cdot 4 \mathrm{H}_{2} \mathrm{O}$ in different solvents including $\mathrm{EtOH}$, $\mathrm{H}_{2} \mathrm{O}, \mathrm{CH}_{2} \mathrm{Cl}_{2}$, and $\mathrm{CH}_{3} \mathrm{CN}$. As shown, low to moderate yields were obtained in the tested solvents. Therefore, our optimized conditions are $3 \mathrm{~mol} \%$ of $\mathrm{Ce}\left(\mathrm{SO}_{4}\right)_{2} \cdot 4 \mathrm{H}_{2} \mathrm{O}$ at $120{ }^{\circ} \mathrm{C}$ under solvent-free conditions. All subsequent reactions were carried out using these conditions.

To determine the scope of the novel protocol, a range of 2,3-dihydroquinazolin-4(1H)-ones were prepared by the reaction of isatoic anhydride, aromatic aldehydes, and ammonium

\section{Table 1}

Optimization of reaction conditions for the synthesis of compound 4a catalyzed by $\mathrm{Ce}\left(\mathrm{SO}_{4}\right)_{2} \cdot 4 \mathrm{H}_{2} \mathrm{O}$.

\begin{tabular}{lccccc}
\hline Entry & $\begin{array}{c}\text { Catalyst } \\
(\mathrm{mol} \%)\end{array}$ & Solvent & $\begin{array}{c}T \\
\left({ }^{\circ} \mathrm{C}\right)\end{array}$ & $\begin{array}{c}\text { Time } \\
(\mathrm{min})\end{array}$ & $\begin{array}{c}\text { Isolated yield } \\
(\%)\end{array}$ \\
\hline 1 & - & - & 120 & 120 & - \\
2 & 1 & - & 100 & 120 & 59 \\
3 & 1 & - & 120 & 90 & 72 \\
4 & 3 & - & 90 & 90 & 58 \\
5 & 3 & - & 100 & 60 & 71 \\
6 & 3 & - & 110 & 60 & 83 \\
7 & 3 & - & 120 & 45 & 95 \\
8 & 3 & - & 140 & 50 & 94 \\
9 & 5 & - & 100 & 60 & 72 \\
10 & 5 & - & 110 & 60 & 82 \\
11 & 5 & - & 120 & 45 & 93 \\
12 & 7 & - & 120 & 50 & 92 \\
13 & 3 & $\mathrm{EtOH}^{2}$ & Reflux & 120 & 58 \\
14 & 3 & $\mathrm{H}_{2} \mathrm{O}$ & Reflux & 120 & 41 \\
15 & 3 & $\mathrm{CH}_{2} \mathrm{Cl}{ }_{2}$ & Reflux & 120 & 30 \\
16 & 3 & $\mathrm{CH}_{3} \mathrm{CN}$ & Reflux & 120 & 45 \\
\hline
\end{tabular}

Reaction conditions: isatoic anhydride $1 \mathrm{mmol}$, benzaldehyde $1 \mathrm{mmol}$, ammonium acetate $1.2 \mathrm{mmol}$. 
acetate or methylamine in the presence of $\mathrm{Ce}\left(\mathrm{SO}_{4}\right)_{2} \cdot 4 \mathrm{H}_{2} \mathrm{O}$ under the optimized reaction conditions. The results are summarized in Table 2. As shown, all reactions proceed very cleanly to give the corresponding 2,3-dihydroquinazolin-4(1H)-one products 4a-4k in high yields over short reaction times, and no undesirable side-products were observed.
To compare the efficiency of ammonium salts in the synthesis of 2,3-dihydroquinazolin-4(1H)-ones, the reactions were also carried out using ammonium carbonate and ammonium chloride under the same reaction conditions. In all cases, the corresponding 2,3-dihydroquinazolin-4(1H)-one was produced in high yield over short reaction time (Table 2).

Table 2

Synthesis of 2,3-dihydroquinazolin- $4(1 \mathrm{H})$-ones $\mathbf{4 a - 4} \mathbf{k}$ using $\mathrm{Ce}\left(\mathrm{SO}_{4}\right)_{2} \cdot 4 \mathrm{H}_{2} \mathrm{O}$ catalyst.

\begin{tabular}{|c|c|c|c|c|c|c|c|}
\hline \multirow{2}{*}{ Product* } & \multirow{2}{*}{$\mathrm{R}$} & \multirow{2}{*}{$\mathrm{Ar}$} & \multirow{2}{*}{$\mathrm{X}$} & \multirow{2}{*}{$\begin{array}{l}\text { Time } \\
\text { (min) }\end{array}$} & \multirow{2}{*}{$\begin{array}{c}\text { Isolated yield } \\
(\%)\end{array}$} & \multicolumn{2}{|c|}{ Melting point $\left({ }^{\circ} \mathrm{C}\right)$} \\
\hline & & & & & & Found & Reported \\
\hline \multirow[t]{3}{*}{$4 \mathrm{a}$} & $\mathrm{H}$ & $\mathrm{C}_{6} \mathrm{H}_{5}$ & OAc & 45 & 95 & $218-219$ & $219-221$ [15] \\
\hline & & & $\mathrm{Cl}$ & 50 & 95 & & \\
\hline & & & $\mathrm{CO}_{3}$ & 35 & 97 & & \\
\hline \multirow[t]{3}{*}{$4 b$} & $\mathrm{H}$ & $4-\mathrm{ClC}_{6} \mathrm{H}_{4}$ & OAc & 50 & 90 & $205-206$ & $198-200$ [15] \\
\hline & & & $\mathrm{Cl}$ & 50 & 92 & & \\
\hline & & & $\mathrm{CO}_{3}$ & 30 & 93 & & \\
\hline \multirow[t]{3}{*}{$4 c$} & $\mathrm{H}$ & $2-\mathrm{ClC}_{6} \mathrm{H}_{4}$ & OAc & 50 & 88 & $215-217$ & 203-205 [19] \\
\hline & & & $\mathrm{Cl}$ & 50 & 85 & & \\
\hline & & & $\mathrm{CO}_{3}$ & 40 & 91 & & \\
\hline \multirow[t]{3}{*}{$4 d$} & $\mathrm{H}$ & $4-\mathrm{BrC}_{6} \mathrm{H}_{4}$ & OAc & 35 & 90 & $200-202$ & 201-203 [21] \\
\hline & & & $\mathrm{Cl}$ & 35 & 90 & & \\
\hline & & & $\mathrm{CO}_{3}$ & 30 & 93 & & \\
\hline \multirow[t]{3}{*}{$4 e$} & $\mathrm{H}$ & $4-\mathrm{MeC}_{6} \mathrm{H}_{4}$ & OAc & 45 & 86 & $233-234$ & $234-236$ [15] \\
\hline & & & $\mathrm{Cl}$ & 50 & 85 & & \\
\hline & & & $\mathrm{CO}_{3}$ & 30 & 92 & & \\
\hline \multirow[t]{3}{*}{$4 f$} & $\mathrm{H}$ & $4-\mathrm{MeOC}_{6} \mathrm{H}_{4}$ & OAc & 45 & 87 & 190-192 & $182-184$ [19] \\
\hline & & & $\mathrm{Cl}$ & 50 & 89 & & \\
\hline & & & $\mathrm{CO}_{3}$ & 30 & 91 & & \\
\hline \multirow[t]{3}{*}{$4 \mathrm{~g}$} & $\mathrm{H}$ & 2-thienyl & OAc & 35 & 90 & $218-220$ & $216-219$ [21] \\
\hline & & & $\mathrm{Cl}$ & 40 & 86 & & \\
\hline & & & $\mathrm{CO}_{3}$ & 30 & 90 & & \\
\hline $4 h$ & $\mathrm{CH}_{3}$ & $\mathrm{C}_{6} \mathrm{H}_{5}$ & - & 45 & 85 & $169-171$ & $164-166$ [15] \\
\hline $4 \mathbf{i}$ & $\mathrm{CH}_{3}$ & $4-\mathrm{ClC}_{6} \mathrm{H}_{4}$ & - & 45 & 85 & $205-207$ & $201-203[16]$ \\
\hline $4 j$ & $\mathrm{CH}_{3}$ & $4-\mathrm{MeOC}_{6} \mathrm{H}_{4}$ & - & 40 & 90 & $146-148$ & $145-147$ [15] \\
\hline $4 k$ & $\mathrm{CH}_{3}$ & $4-\mathrm{NO}_{2} \mathrm{C}_{6} \mathrm{H}_{4}$ & - & 40 & 86 & $198-200$ & 200-202 [19] \\
\hline
\end{tabular}

Reaction conditions: isatoic anhydride $\mathbf{1}(1 \mathrm{mmol})$, aromatic aldehyde $\mathbf{2}(1 \mathrm{mmol})$, a nitrogen source $\mathbf{3}$ (ammonium acetate $1.2 \mathrm{mmol}$, ammonium carbonate $0.6 \mathrm{mmol}$, ammonium chloride $1.2 \mathrm{mmol}$, or methyl amine $1.2 \mathrm{mmol}), \mathrm{Ce}\left(\mathrm{SO}_{4}\right)_{2} \cdot 4 \mathrm{H}_{2} \mathrm{O}(0.03 \mathrm{mmol}, 3 \mathrm{~mol} \%$ based on isatoic anhydride), 120 ${ }^{\circ} \mathrm{C}$, solvent-free.

*All the products were characterized by their IR spectral data and a comparison of their melting points with those of authentic samples. The structures of some products were also confirmed by ${ }^{1} \mathrm{H}$ NMR analysis.

Table 3

Comparison of the efficiencies of different catalysts for the one-pot three-component synthesis of 2,3-dihydroquinazolin-4(1H)-ones.

\begin{tabular}{|c|c|c|c|c|c|c|}
\hline \multirow{2}{*}{ Catalyst } & \multicolumn{3}{|c|}{ Conditions } & \multirow{2}{*}{ Time (min) } & \multirow{2}{*}{ Yield (\%) } & \multirow{2}{*}{ Ref. } \\
\hline & Solvent & $T /{ }^{\circ} \mathrm{C}$ & Other & & & \\
\hline$[\mathrm{bmim}] \mathrm{HSO}_{4}$ & $\mathrm{H}_{2} \mathrm{O}$ & reflux & - & $150-240$ & $70-91$ & [13] \\
\hline Silica sulfuric acid & $\mathrm{H}_{2} \mathrm{O}$ & 80 & - & $180-330$ & $75-89$ & [14] \\
\hline Silica sulfuric acid & - & 80 & - & $240-360$ & $70-83$ & [14] \\
\hline Copolymer-PTSA & EtOH & reflux & - & $200-420$ & $70-94$ & [15] \\
\hline Trifluoroethanol & $\mathrm{CF}_{3} \mathrm{CH}_{2} \mathrm{OH}$ & reflux & - & 180 & $80-97$ & [16] \\
\hline Thiamine hydrochloride & EtOH & reflux & - & $120-360$ & $75-94$ & [17] \\
\hline Cu-CNTs nanocomposite & - & - & MW & $5-23$ & $87-99$ & [18] \\
\hline Aluminum methanesulfonate & $\mathrm{EtOH} / \mathrm{H}_{2} \mathrm{O}$ & reflux & - & $30-420$ & $33-96$ & [19] \\
\hline Montmorillonite K-10 & EtOH & reflux & - & $180-420$ & $70-95$ & {$[20]$} \\
\hline Silica-bonded $S$-sulfonic acid & EtOH & reflux & - & $35-240$ & $75-90$ & {$[21]$} \\
\hline Acetic acid & $\mathrm{AcOH}$ & reflux & - & $60-150$ & $79-92$ & [22] \\
\hline $\mathrm{KAl}\left(\mathrm{SO}_{4}\right)_{2} \cdot 12 \mathrm{H}_{2} \mathrm{O}$ & $\mathrm{EtOH}$ & reflux & - & $180-360$ & $69-92$ & [23] \\
\hline Silica-bonded $N$-propylsulfamic acid & EtOH & reflux & - & $150-180$ & $81-88$ & [24] \\
\hline Magnetic $\mathrm{Fe}_{3} \mathrm{O}_{4}$ nanoparticles & $\mathrm{H}_{2} \mathrm{O}$ & reflux & - & $90-360$ & $51-88$ & [25] \\
\hline $\mathrm{Ce}\left(\mathrm{SO}_{4}\right)_{2} \cdot 4 \mathrm{H}_{2} \mathrm{O}$ & - & 120 & - & $30-50$ & $85-97$ & this work \\
\hline
\end{tabular}

MW: microwave. 


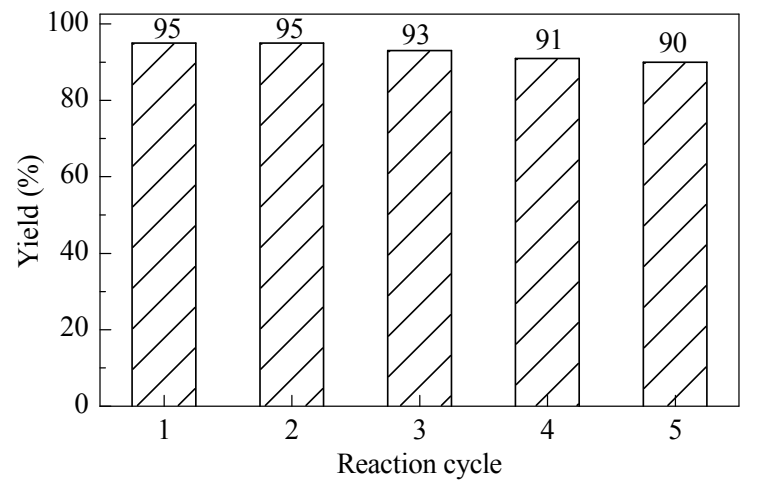

Fig. 1. Effect of recycling on catalytic performance of $\mathrm{Ce}\left(\mathrm{SO}_{4}\right)_{2} \cdot 4 \mathrm{H}_{2} \mathrm{O}$ in the synthesis of $\mathbf{4 a}$ in the model reaction.

To show the merit of this methodology, the results were compared with those using other catalysts reported for the synthesis of 2,3-dihydroquinazolin-4(1H)-ones. As shown in Table 3, our reaction conditions gave a shorter reaction time than all the other conditions (except catalysis by Cu-CNTs nanocomposite with microwave irradiation) and gave high yields of the desired products.

The recyclability of the catalyst was also investigated using the same model reaction. The catalyst was readily recovered from the reaction mixture using the procedure outlined in the experimental section. The separated catalyst was washed with hot ethanol and subsequently dried at $60{ }^{\circ} \mathrm{C}$ under vacuum for $2 \mathrm{~h}$ before being reused in a similar reaction. The recovered yields of the catalyst were 99\%, 98\%, 98\%, 99\%, and 98\% in runs 1 to 5 , respectively. The recycled catalyst in each run (1 to 4) was just used for the next run. The results show that the catalyst can be used at least five times without substantial reduction in its catalytic activity (Fig. 1). Furthermore, retention of the structure of the catalyst was confirmed by comparing the FT-IR spectra of the recovered catalyst after the fifth run with that of the fresh catalyst for the model reaction (Fig. 2). As shown, these spectra are almost identical.

\section{Conclusions}

We have demonstrated the efficiency of $\mathrm{Ce}\left(\mathrm{SO}_{4}\right)_{2} \cdot 4 \mathrm{H}_{2} \mathrm{O}$ as a novel inorganic solid acidic catalyst for the preparation of

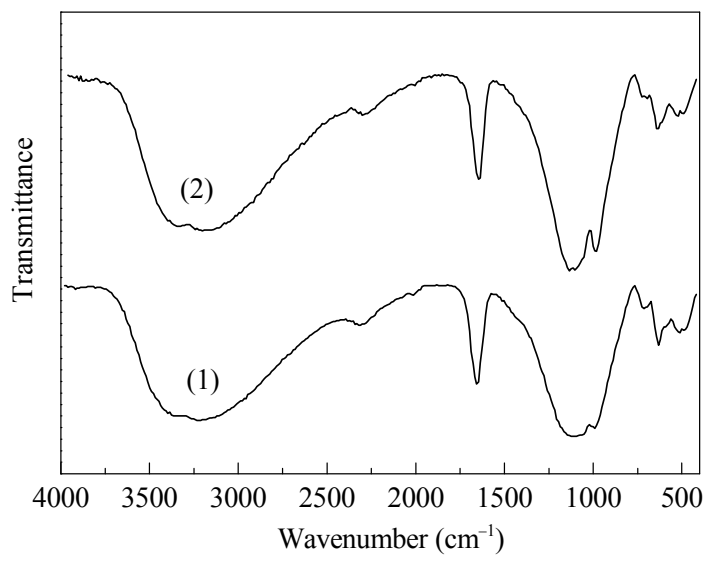

Fig. 2. FT-IR spectra of fresh catalyst $\mathrm{Ce}\left(\mathrm{SO}_{4}\right)_{2} \cdot 4 \mathrm{H}_{2} \mathrm{O}$ (1) and recovered catalyst after the fifth run (2) for synthesis of compound $\mathbf{4 a}$ in the model reaction.

2,3-dihydroquinazolin-4(1H)-ones via the one-pot three-component reaction of isatoic anhydride, aromatic aldehydes, and a nitrogen source (ammonium acetate, ammonium carbonate, ammonium chloride, or methylamine) under solvent-free conditions. A variety of aromatic aldehydes participated well in the reaction affording the expected products in high yields with short reaction times and simple work-up. Furthermore, the catalyst could be easily recycled and reused at least five times without significant reduction in its catalytic activity. The procedure is also advantageous because it is a solvent-free reaction and therefore operates under environmentally friendly conditions.

\section{References}

[1] Dömling A. Chem Rev, 2006, 106: 17

[2] Zeinali-Dastmalbaf M, Davoodnia A, Heravi M M, Tavakoli-Hoseini N, Khojastehnezhad A, Zamani H A. Bull Korean Chem Soc, 2011, 32: 656

[3] Davoodnia A, Khojastehnezhad A.J Chil Chem Soc, 2012, 57: 1385

[4] Sadanadam Y S, Reddy K R M, Rao A B. Eur J Med Chem, 1987, 22: 169

[5] Hour M J, Huang L J, Kuo S C, Xia Y, Bastow K, Nakanishi Y, Hamel E, Lee K H.J Med Chem, 2000, 43: 4479

[6] Davoodnia A, Allameh S, Fakhari A R, Tavakoli-Hoseini N. Chin

\section{Graphical Abstract}

Chin. J. Catal., 2014, 35: 1054-1058 doi: 10.1016/S1872-2067(14)60041-3

Cerium (IV) sulfate: A highly efficient reusable heterogeneous catalyst for one-pot synthesis of 2,3-dihydroquinazolin-4(1H)-ones under solvent-free conditions

Abolghasem Davoodnia*, Maryam Khashi, Niloofar Tavakoli-Hoseini Islamic Azad University, Iran

Synthesis of 2,3-dihydroquinazolin-4(1H)-ones via the one-pot reaction of isatoic anhydride, aromatic aldehydes, and a nitrogen source (an ammonium salt or methylamine) is efficiently catalyzed by $\mathrm{Ce}\left(\mathrm{SO}_{4}\right)_{2} \cdot 4 \mathrm{H}_{2} \mathrm{O}$ under solvent-free conditions. The catalyst could be easily recycled and used at least five times without significant reduction in its activity. 
Chem Lett, 2010, 21: 550

[7] Chen J X, Wu H Y, Su W K. Chin Chem Lett, 2007, 18: 536

[8] Yassaghi G, Davoodnia A, Allameh S, Zare-Bidaki A, Tavakoli-Hoseini N. Bull Korean Chem Soc, 2012, 33: 2724

[9] Wang J K, Zong Y X, Fu R G, Niu Y Y, Yue G R, Quan Z G, Wang X C, Pan Y. Ultrason Sonochem, 2014, 21: 29

[10] Li S W, Nair M G, Edwards D M, Kisliuk R L, Gaumont Y, Dev I K, Duch D S, Hmphrys J, Smith G K, Ferone R. J Med Chem, 1991, 34: 2746

[11] Moore J A, Sutherland G J, Sowerby R, Kelly E G, Palermo S, Webster W.J Org Chem, 1969, 34: 887

[12] Yale H L. J Heterocycl Chem, 1977, 14: 1357

[13] Darvatkar N B, Bhilare S V, Deorukhkar A R, Raut D G, Salunkhe M M. Green Chem Lett Rev, 2010, 3: 301

[14] Dabiri M, Salehi P, Baghbanzadeh M, Zolfigol M A, Agheb M, Heydari S. Catal Commun, 2008, 9: 785

[15] Saffar-Teluri A, Bolouk S. Monatsh Chem, 2010, 141: 1113

[16] Khaksar S, Mohammadzadeh Talesh S. C R Chim, 2012, 15: 779

[17] Chen Y J, Shan W G, Lei M, Hu L H. Tetrahedron Lett, 2012, 53 : 5923

[18] Safari J, Gandomi-Ravandi S. J Mol Catal A, 2013, 371: 135

[19] Song Z G, Liu L L, Wang Y, Sun X H. Res Chem Intermed, 2012, 38: 1091

[20] Salehi P, Dabiri M, Baghbanzadeh M, Bahramnejad M. Synth Commun, 2006, 36: 2287

[21] Niknam K, Mohammadizadeh M R, Mirzaee S. Chin J Chem, 2011, 29: 1417

[22] Karimi-Jaberi Z, Arjmandi R. Monatsh Chem, 2011, 142: 631

[23] Dabiri M, Salehi P, Otokesh S, Baghbanzadeh M, Kozehgary G, Mohammadi A A. Tetrahedron Lett, 2005, 46: 6123

[24] Niknam K, Jafarpour N, Niknam E. Chin Chem Lett, 2011, 22: 69
[25] Zhang Z H, Lu H Y, Yang S H, Gao J W. J Comb Chem, 2010, 12: 643

[26] Horiuchi C A, Fukushima T, Furuta N, Chai W, Ji S J, Saito Y, Hashimoto C, Takahashi T T, Sugiyama T, Muto A, Sakata Y, Nozaki S. J Chem Res (R), 2003: 270

[27] Selvam N P, Perumal P T. Tetrahedron Lett, 2006, 47: 7481

[28] He L Y, Horiuchi C A. Appl Organometal Chem, 1999, 13: 867

[29] Itoh K, Takahashi S, Ueki T, Sugiyama T, Takahashi T T, Horiuchi C A. Tetrahedron Lett, 2002, 43: 7035

[30] Ko S, Yao C F. Tetrahedron, 2006, 62: 7293

[31] Davoodnia A, Zare-Bidaki A, Behmadi H. Chin J Catal (催化学报), 2012, 33: 1797

[32] Zeinali-Dastmalbaf M, Davoodnia A, Heravi M M, Tavakoli-Hoseini N, Khojastehnezhad A, Zamani H A. Bull Korean Chem Soc, 2011, 32: 656

[33] Davoodnia A, Khojastehnezhad A, Tavakoli-Hoseini N. Bull Korean Chem Soc, 2011, 32: 2243

[34] Mohammadzadeh-Dehsorkh N, Davoodnia A, Tavakoli-Hoseini N, Moghaddas M. Synth React Inorg Met-Org Nano-Met Chem, 2011, 41: 1135

[35] Emrani A, Davoodnia A, Tavakoli-Hoseini N. Bull Korean Chem Soc, 2011, 32: 2385

[36] Davoodnia A, Khashi M, Tavakoli-Hoseini N. Chin J Catal (催化学 报), 2013, 34: 1173

[37] Khojastehnezhad A, Davoodnia A, Bakavoli M, Tavakoli-Hoseini N, Zeinali-Dastmalbaf M. Chin J Chem, 2011, 29: 297

[38] Seifi N, Zahedi-Niaki M H, Reza Barzegari M, Davoodnia A, Zhiani R, Kaju A A. J Mol Catal A, 2006, 260: 77

[39] Taghavi-Khorasani F, Davoodnia A. Res Chem Intermed, in press, doi: 10.1007/s11164-013-1356-0

[40] Saburi E, Davoodnia A, Tavakoli-Hoseini N. Synth React Inorg Met-Org Nano-Met Chem, 2011, 41: 1063 